\title{
A potential vorticity-based determination of the transport barrier in the Asian summer monsoon anticyclone
}

\author{
F. Ploeger, C. Gottschling, S. Griessbach, J.-U. Grooß, G. Guenther, P. Konopka, R. Müller, M. Riese, F. Stroh, \\ M. Tao, J. Ungermann, B. Vogel, and M. von Hobe \\ Institute for Energy and Climate research: Stratosphere (IEK-7), Forschungszentrum Jülich, Jülich, Germany \\ Correspondence to: F. Ploeger (f.ploeger@fz-juelich.de)
}

Received: 20 February 2015 - Published in Atmos. Chem. Phys. Discuss.: 13 April 2015

Revised: 28 October 2015 - Accepted: 15 November 2015 - Published: 27 November 2015

\begin{abstract}
The Asian summer monsoon provides an important pathway of tropospheric source gases and pollution into the lower stratosphere. This transport is characterized by deep convection and steady upwelling, combined with confinement inside a large-scale anticyclonic circulation in the upper troposphere and lower stratosphere (UTLS). In this paper, we show that a barrier to horizontal transport along the $380 \mathrm{~K}$ isentrope in the monsoon anticyclone can be determined from a local maximum in the gradient of potential vorticity (PV), following methods developed for the polar vortex (e.g., Nash et al., 1996). The monsoon anticyclone is dynamically highly variable and the maximum in the PV gradient is weak, such that additional constraints are needed (e.g., time averaging). Nevertheless, PV contours in the monsoon anticyclone agree well with contours of trace gas mixing ratios $\left(\mathrm{CO}, \mathrm{O}_{3}\right)$ and mean age from model simulations with a Lagrangian chemistry transport model (CLaMS) and satellite observations from the Microwave Limb Sounder (MLS) instrument. Hence, the PV-based transport barrier reflects the separation between air inside the core of the anticyclone and the background atmosphere well. For the summer season 2011 we find an average PV value of 3.6 PVU for the transport barrier in the anticyclone on the $380 \mathrm{~K}$ isentrope.
\end{abstract}

\section{Introduction}

An efficient pathway for anthropogenic pollution and tropospheric source gases into the stratosphere is linked to the Asian summer monsoon, as has been shown from satellite observations of HCN (Randel et al., 2010). Upward transport in the monsoon is caused by frequent high-reaching convection (e.g., Tzella and Legras, 2011; Bergman et al., 2012) and slower steady upwelling at higher levels around the tropopause. In the upper troposphere and lower stratosphere (UTLS), more precisely in the Tropical Tropopause Layer TTL (e.g., Fueglistaler et al., 2009), the Asian monsoon is characterized by a large-scale anticyclonic circulation system, mainly a response to strong convective diabatic heating at low levels (Gill, 1980). The anticyclonic circulation confines the upward transported air and isolates it, to some degree, from its surroundings. This confinement leads to positive anomalies of tropospheric trace gases (e.g., $\mathrm{CO}$, $\mathrm{HCN}, \mathrm{H}_{2} \mathrm{O}$ ) and to negative anomalies of stratospheric trace gases (e.g., ozone) in the anticyclone (e.g., Randel and Park, 2006; Park et al., 2007, 2008; James et al., 2008; Bian et al., 2012).

For an improved understanding of the pollution transport by the monsoon, understanding the confinement of trace gases within the anticyclone is crucial. However, the Asian monsoon anticyclone is characterized by large dynamic variability (Garny and Randel, 2013), strong east-west displacements (Krishnamurti et al., 1973), frequent shedding of small-scale eddies (Hsu and Plumb, 2000; Popovich and Plumb, 2001) and even splits. Moreover, strong diabatic heating processes play a role in the monsoon and, consequently, potential vorticity (PV) is not well conserved (e.g., Holton, 1992). For these reasons, the confinement of air inside the Asian monsoon anticyclone appears to be much weaker than in the polar vortex, and it turns out to be very challenging to locate a barrier to horizontal transport (Garny and Randel, 2013). However, that such a transport barrier exists, at least to some degree, is reflected in the observed trace gas anomalies within the anticyclone. 
To date, simplified criteria have been adopted to define this transport barrier and to separate the core region of the anticyclone from its surroundings. These criteria are commonly based on the positive geopotential height anomaly or the negative PV anomaly in the monsoon anticyclone and assume a fixed geopotential height (on a fixed pressure level) or PV value to represent the transport barrier (e.g., Randel and Park, 2006; Bergman et al., 2013). These criteria have the advantage of being easy to apply, but they lack a clear physical reasoning.

In this paper, we present a physically motivated criterion to deduce the transport barrier in the Asian monsoon anticyclone based on conservation properties of the flow. This criterion is closely related to a well-established methodology using PV gradients on isentropic surfaces, which has been originally developed for the polar vortex (e.g., Butchart and Remsberg, 1986; Manney et al., 1994; Nash et al., 1996). The method relies on the fact that PV is approximately conserved, such that a maximum in the PV gradient on an isentrope reflects the existence of a barrier to transport. We emphasize here that the terminology "transport barrier" does not imply vanishing cross-gradient transport. In fact, the anticyclone transport barrier turns out to be rather leaky and is better interpreted as a region of reduced cross-gradient transport (see Sect. 7).

We introduce the data, model and methods to be used in Sect. 2. In Sect. 3 we motivate the use of PV as a basis for deducing the anticyclone transport barrier, by comparing PV to simulated and observed trace gas distributions (CO, $\mathrm{O}_{3}$ ) in the Asian monsoon region. The criterion for deducing the transport barrier is presented in Sect. 4, and validated by comparison to simulated CO, ozone and mean age in Sect. 5. We finally discuss our results and conclude.

\section{Methods}

Meteorological fields to characterize the Asian monsoon anticyclone are taken from European Centre for MediumRange Weather Forecasts (ECMWF) ERA-Interim reanalysis. ERA-Interim covers the period from 1979 until present, assimilating observational data from several sources to provide a reliable state of the atmosphere (for details, see Dee et al., 2011). We used 6-hourly data on a $1^{\circ} \times 1^{\circ}$ horizontal grid and interpolated it on potential temperature $(\theta)$ levels in the vertical. The presented analysis focuses on the summer season (June-August, JJA) 2011 and on the $380 \mathrm{~K}$ isentropic surface, which is a characteristic level for the Asian upper-level anticyclone in the UTLS. Note that in the tropics $380 \mathrm{~K}$ is close to the $100 \mathrm{hPa}$ isobaric surface, which has been used in several studies to analyze transport in the Asian monsoon anticyclone (e.g., Randel and Park, 2006; Bergman et al., 2013).

The most relevant meteorological fields for this study are Ertel's potential vorticity $(\mathrm{PV})$, the circulation $(\Gamma)$, and the
Montgomery stream function $(M)$. PV is calculated from the horizontal winds (e.g., Holton, 1992):

$\mathrm{PV}=\sigma^{-1}(\zeta+f)$

with $\zeta$ the relative vorticity, $f=2 \Omega \sin \phi$ the Coriolis parameter, and $\sigma=-g^{-1} \partial_{\theta} p$ the isentropic mass density ( $p$ pressure, $\phi$ latitude, $g$ acceleration due to gravity, and $\Omega$ the rotation frequency of the Earth). PV is a particularly wellsuited quantity for characterizing barriers to transport. In the absence of friction and diabatic processes the PV of an air parcel is conserved following its motion (e.g., Holton, 1992), and thus regions of enhanced PV gradients are indicative of suppressed transport (transport barriers). This fact was used for the polar vortex to deduce the transport barrier based on the gradient of PV along an isentropic surface (e.g., Manney et al., 1994; Nash et al., 1996).

A related quantity, characterizing fluid rotation, is the circulation $\Gamma$ along a closed contour $S$ (here, on an isentrope):

$\Gamma=\oint_{S} \boldsymbol{d} s \cdot \boldsymbol{v}=\int_{A} d a \zeta$,

with $A$ the area enclosed by the contour $S$ and $v=(u, v)$ the horizontal wind on an isentropic surface ( $\boldsymbol{d} s$ and $d a$ represent line and area elements). Therefore, cyclonic flow is characterized by positive circulation, while anticyclonic flow is characterized by negative circulation.

The Montgomery stream function $M=c_{\mathrm{p}} T+\Phi$ (with $\Phi$ geopotential, $T$ temperature, and $c_{\mathrm{p}}$ the specific heat at constant pressure) is the isentropic analogue of geopotential, which is frequently used to characterize the monsoon anticyclone (Randel and Park, 2006; Bergman et al., 2013). Under geostrophic approximations the horizontal flow on an isentrope is along contours of constant $M$ (e.g., Holton, 1992).

Due to the anticyclonic nature of the upper-level circulation, the Asian monsoon in the UTLS is characterized by strongly negative, anomalously low PV (see Fig. 1), and anomalously high Montgomery stream function values. To the north, the anticyclone is bounded by the subtropical westerly jet, to the south by the equatorial easterly jet. Furthermore, the monsoon region is characterized by an elevated thermal tropopause which, from a climatological point of view, exceeds the zonal mean tropopause by more than $1 \mathrm{~km}$ (Fig. 1), corresponding to $\approx 20 \mathrm{~K}$ in potential temperature.

To confirm the deduced location of the transport barrier, which will be based on PV, we consider different trace gas species (carbon monoxide, ozone) from model simulations with the Chemical Lagrangian Model of the Stratosphere CLaMS (McKenna et al., 2002b, a; Konopka et al., 2007), driven by ERA-Interim meteorological data. We further consider simulated mean age of air, the average transit time for transport through the stratosphere, calculated from an inert tracer with a linearly increasing source in the model boundary layer (e.g., Waugh and Hall, 2002). CLaMS is a Lagrangian chemistry transport model (CTM), based on 3-D 


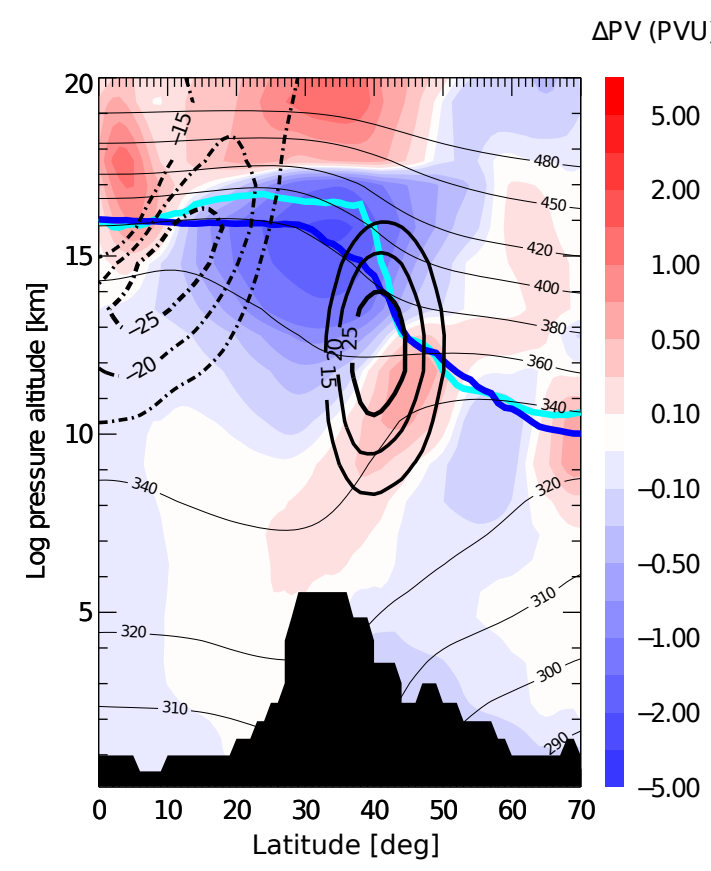

Figure 1. Meteorological conditions in the Asian monsoon anticyclone (based on ERA-Interim reanalysis). Color shading shows the $\mathrm{PV}$ anomaly of the monsoon longitude section $\left(60-120^{\circ} \mathrm{E}\right)$ with respect to the zonal mean, averaged over summer (June-August). Also shown is zonal wind (thick black, solid/dashed positive/negative) and potential temperature (thin black) averaged between $60-120^{\circ} \mathrm{E}$. The first thermal tropopause (calculated using the definition of WMO, 1957) zonally averaged over $0-360^{\circ} \mathrm{E}$ is shown as darkblue, averaged over $60-120^{\circ} \mathrm{E}$ as cyan line.

forward trajectories, with an additional parameterization for small-scale mixing, which depends on the deformation in the large-scale flow. Vertical transport in the model is purely diabatic above about $300 \mathrm{hPa}$, with the total diabatic heating rates taken from ERA-Interim forecast data. The vertical model resolution around the tropopause is about $400 \mathrm{~m}$. For the simulation of $\mathrm{CO}$, a lower boundary condition from MOPITT (Measurements of Pollution in the Troposphere satellite experiment) is used and chemical loss due to reaction with $\mathrm{OH}$ is included as described in Pommrich et al. (2014). CLaMS ozone includes a zero mixing ratio lower boundary condition and a simplified chemistry comprising photolytical production and loss due to the $\mathrm{HO}_{x}$ driven catalytic ozone loss cycle in the lower stratosphere. For further details about this specific CLaMS simulation see Pommrich et al. (2014). In the UTLS, CLaMS CO and ozone agree well with various observations, as shown in several recent publications (e.g., Pommrich et al., 2014; Konopka et al., 2010).

In addition, results will be compared to ozone observations from the Microwave Limb Sounder (MLS) instrument onboard the Aura satellite version 3 data (see e.g., Livesey et al., 2008, and http://mls.jpl.nasa.gov/data/v3 data_quality_document.pdf). MLS scans about 3500 profiles per day providing a dense sampling of the global atmosphere, including the Asian monsoon region. The vertical resolution of MLS ozone is about $3 \mathrm{~km}$. For MLS CO, a standard tropospheric tracer for Asian monsoon studies, the vertical resolution is coarser $(\approx 4.5 \mathrm{~km})$ and therefore we focus on ozone for this study. MLS profiles are originally on pressure levels and were interpolated to potential temperature surfaces for the purpose of this study. For further details about MLS data, see Livesey et al. (2008).

\section{Trace gas confinement in the anticyclone and PV}

Figure 2a and b show the distributions of CLaMS CO and ozone in the monsoon region on the $380 \mathrm{~K}$ isentrope on 6 July 2011. Clearly visible is the positive anomaly of the tropospheric tracer CO and the negative anomaly of the stratospheric tracer ozone in the monsoon anticyclone, characteristic for strong tropospheric impact and confinement within the anticyclone. Note that extratropical stratospheric air is advected around the eastern flank of the anticyclone, transporting CO-poor and ozone-rich air equatorwards. This transport has recently been shown to strongly affect the ozone seasonality in the tropics (Konopka et al., 2010; Ploeger et al., 2012; Abalos et al., 2013). Furthermore, poleward transport of COrich air affects the trace gas composition of the lowermost stratosphere and crucially depends on the CO lifetime (e.g., Hoor et al., 2010). To create a similar map from ozone measurements, we bin ozone observations from MLS between 4 and 8 July 2011 (using version 3.3 data), in order to obtain sufficiently dense observations (Fig. 2c). Lower ozone mixing ratios in the model compared to MLS are likely related to the broad satellite averaging kernel and the zero mixing ratio boundary condition at the surface in the model (Pommrich et al., 2014). However, the patterns of the low ozone anomaly in the monsoon anticyclone reliably agree between model simulations and observations (note the 5-day average for the satellite data).

Overlaid on the trace gas mixing ratios in Fig. 2 are contours of PV and Montgomery stream function. Both meteorological quantities show strong anomalies within the monsoon. However, when compared to the trace gas mixing ratio contours the PV contours agree better than the Montgomery stream function contours, in particular for small-scale variations. Even the separation of a smaller eddy to the east of the main anticyclone is well reflected in the PV distribution. These small-scale eddies, frequently shed from the main anticyclone, have the potential to transport air masses with elevated mixing ratios of tropospheric trace gases (e.g., $\mathrm{CO}$, $\mathrm{H}_{2} \mathrm{O}$ ) rapidly into the middle and high latitude lower stratosphere (e.g., Ploeger et al., 2013; Vogel et al., 2014). A close relation between the distributions of $\mathrm{CO}$ and $\mathrm{PV}$ in the monsoon was already found by Garny and Randel (2013). For these reasons, we use PV as a basis for defining a criterion for the transport barrier in the Asian monsoon. 

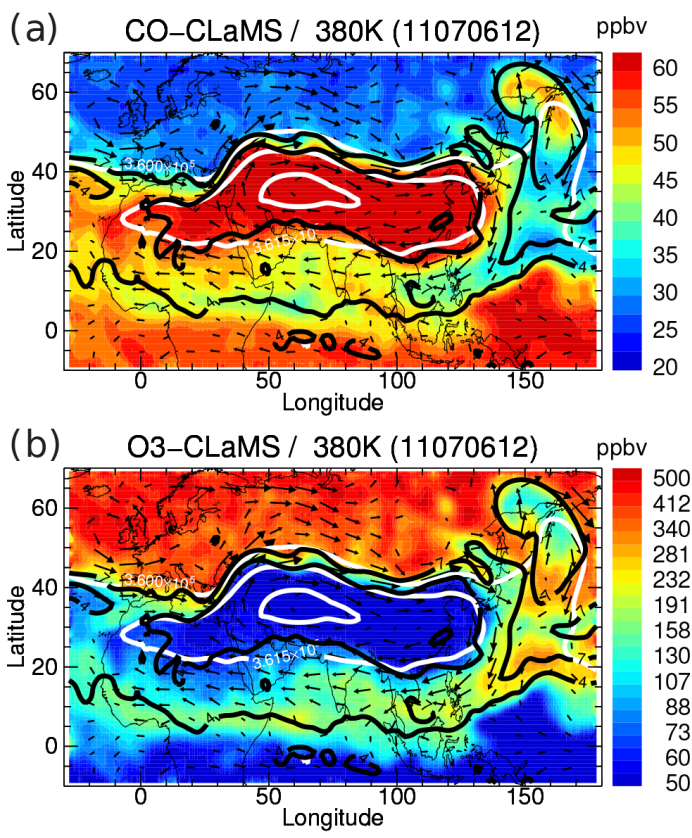

(c) O3-MLS / 380K (11070412-11070812) ppbv

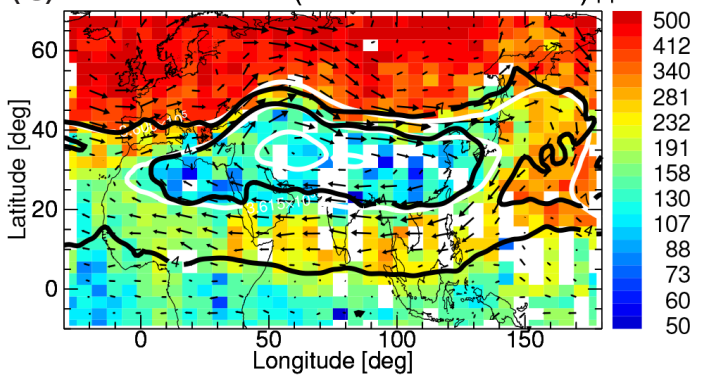

Figure 2. Maps of (a) CLaMS CO and (b) CLaMS ozone on the $380 \mathrm{~K}$ isentrope on 6 July 2011 within the Asian monsoon region. Selected potential vorticity contours are shown in black (4, 7 PVU) and Montgomery stream function contours in white $\left(3.6 \times 10^{5}\right.$, $3.615 \times 10^{5} \mathrm{~m}^{2} \mathrm{~s}^{-2}$ ). Arrows show horizontal wind. (c) Same but for MLS ozone data sampled during the period 4-8 July 2011, with the MLS data binned into $3^{\circ} \times 6^{\circ}$ latitude/longitude bins (bins without measurements are left white). Meteorological data are taken from ERA-Interim. (Note the logarithmic color scale for ozone.)

Motivated by studies of the polar vortex where the transport barrier is characterized by particularly steep gradients of conserved tracers, we map MLS and CLaMS ozone vs. potential vorticity (Fig. 3). This mapping was carried out by binning all data from the Asian monsoon region at $380 \mathrm{~K}$ $\left(10-60^{\circ} \mathrm{N}\right.$ and $\left.10^{\circ} \mathrm{W}-160^{\circ} \mathrm{E}\right)$ with respect to potential vorticity (bin size $0.1 \mathrm{PVU}$ ). Figure 3 shows that, despite the offset between CLaMS and MLS ozone mentioned above, there is agreement in the main structure, with low ozone in the core of the anticyclone (at low PV values) and higher mixing ratios towards higher PV. In particular, there is evidence from model and observations for a two-step increase of ozone mixing ratios, resulting in two separate maxima in the gradient of ozone with respect to PV. The stronger maximum around
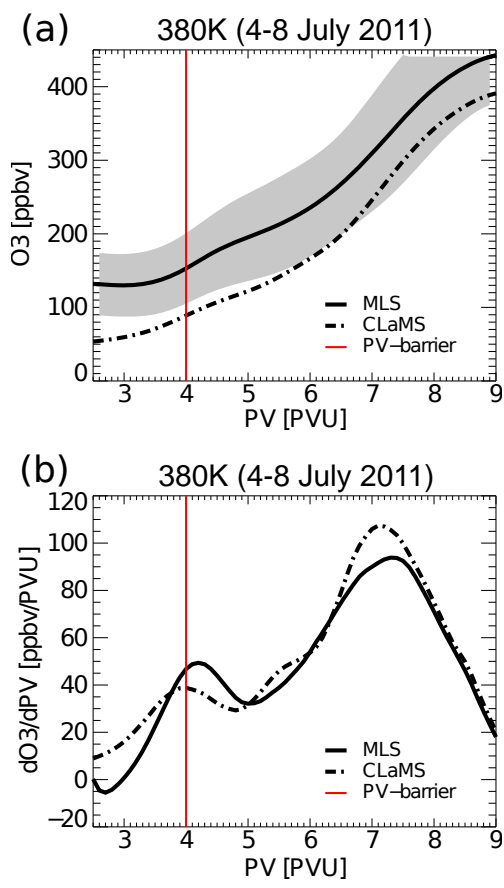

Figure 3. (a) Ozone from MLS (solid) and CLaMS (dashed) vs. potential vorticity in the Asian monsoon region $\left(10-60^{\circ} \mathrm{N}\right.$ and $10^{\circ} \mathrm{W}-$ $160^{\circ} \mathrm{E}$ ) at $380 \mathrm{~K}$, averaged over the period 4-8 June 2011. (b) Same but for the ozone gradient with respect to potential vorticity. Red lines show the transport barrier determined from PV (see text).

$7 \mathrm{PVU}$ is related to the transport barrier at the subtropical jet (Kunz et al., 2011). The secondary maximum occurs around 4 PVU. In the following, we will provide evidence that this secondary maximum may be interpreted as the transport barrier of the Asian monsoon anticyclone (red line shows the transport barrier PV value, objectively determined using the criterion derived in the following section).

\section{A PV-gradient criterion for the Asian monsoon}

Motivated by the good agreement between the PV and trace gas variability in the monsoon region (Fig. 2) and the fact that $\mathrm{PV}$ is an approximately conserved quantity, we follow the approach developed for the polar vortex for deducing a transport barrier (e.g., Butchart and Remsberg, 1986; Manney et al., 1994; Nash et al., 1996). Nash et al. (1996) defined the transport barrier of the vortex edge as the location of the largest (isentropic) change in PV, with the additional constraint of close proximity to a strong zonal jet. Recently, Kunz et al. (2011) deduced the location of the transport barrier for the subtropical jet using an analogous approach.

The PV distribution on 6 July 2011 is shown in Fig. 4, illustrating the anomalously low PV in the Asian monsoon anticyclone. In a first step, we restrict all fields to a region including the monsoon anticyclone, which we define as $10^{\circ} \mathrm{N} \leq \phi \leq 60^{\circ} \mathrm{N}$ and $10^{\circ} \mathrm{W} \leq \lambda \leq 160^{\circ} \mathrm{E}$ ( $\phi$ latitude, $\lambda$ 


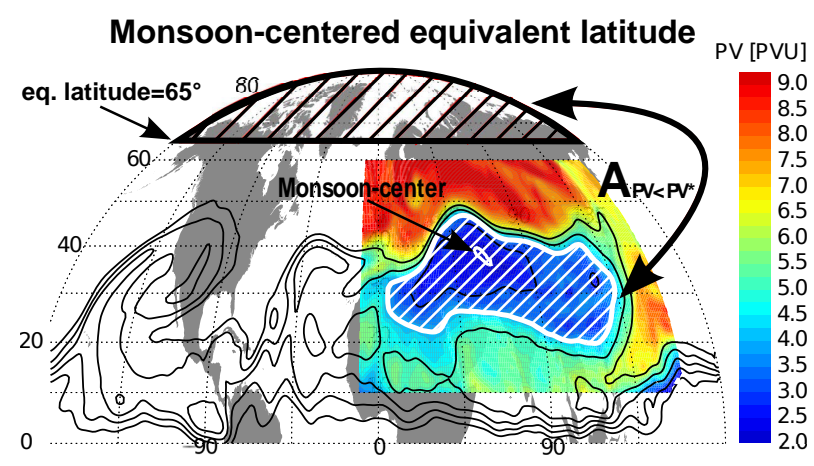

Figure 4. Illustration of the calculation of monsoon-centered equivalent latitude from the area within PV-contours (see text for details). Color-coded is the PV-field within the Asian monsoon region at $380 \mathrm{~K}\left(10-60^{\circ} \mathrm{N}\right.$ and $\left.10^{\circ} \mathrm{W}-160^{\circ} \mathrm{E}\right)$ averaged for 5-7 July 2011 , with the thick white contour highlighting 4 PVU. The thin white contour encloses the region of lowest PV $(<2.2 \mathrm{PVU})$ indicating the anticyclone center. The black contours show PV globally.

longitude) to eliminate the interfering influence of low PV values near the equator. The PV distribution on 6 July 2011 within this region is shown in Fig. 5a (top). A similar definition of the Asian monsoon area was used by Garny and Randel (2013). The chosen latitude-longitude range includes the anticyclone for all days during summer 2011. Slight variations to this range cause no significant change to our results.

Following Butchart and Remsberg (1986), we define a monsoon-centered equivalent latitude $\phi_{\text {eq }}$ of a given PV contour in the anticyclone as the latitude of a circle around the North Pole enclosing the same area, as illustrated in Fig. 4 (here, the $4 \mathrm{PVU}$ contour is mapped to about $\phi_{\mathrm{eq}}=65^{\circ}$ ). Hence, for a PV contour enclosing an area $A$, the equivalent latitude is defined by $A=2 \pi r_{\mathrm{E}}^{2}\left(1-\sin \phi_{\mathrm{eq}}\right)$, with $r_{\mathrm{E}}$ being the Earth's radius. Consequently, the center of the monsoon occurs at a monsoon equivalent latitude of $90^{\circ}$, corresponding to the location of minimum PV. In this sense, PV and equivalent latitude are related to each other, exhibiting a unique functional dependence $\mathrm{PV}\left(\phi_{\mathrm{eq}}\right)$ as shown in Fig. 5a (bottom). As already noted above, PV increases monotonically from low values in the center of the anticyclone to higher values at its edge.

For 6 July 2011, the gradient of PV with respect to $\phi_{\text {eq }}$, namely $\partial \mathrm{PV} / \partial \phi_{\mathrm{eq}}$, shows no clear maximum which could be indicative for the anticyclone transport barrier, besides the maximum around $50^{\circ}$ equivalent latitude (about 7-8 PVU) related to the subtropical jet (Kunz et al., 2011). The absence of a clear secondary maximum, representing the anticyclone transport barrier, has recently been attributed to the large dynamical variability of the anticyclone (Garny and Randel, 2013). However, if this variability is damped by averaging the PV field over a time window of 3 days between 5 and 7 July 2011, a clear secondary maximum in the PV gradient emerges around $65^{\circ}$ equivalent latitude (Fig. 5b, bottom). In the following, we interpret this maximum as the transport barrier of the Asian monsoon anticyclone, and show its physical significance by comparison to trace gas distributions in Sect. 5.

To calculate the time-averaged PV for different dates we use a variable time window. Therefore, we define an optimal window for each date as the smallest number of days ( \pm 3 days at most) such that the PV-gradient maximum exceeds the adjacent minima by $30 \%$. Figure 6 illustrates this procedure for the example of the 6 July 2011, confirming that for this date a \pm 1 -day average (3-day time window) results in the clearest gradient maximum. If the time window chosen is too large (e.g., \pm 3 days in Fig. 6), the maximum in the PV gradient degrades again because different dynamical conditions contribute to the average. For that reason, we restrict the maximum averaging period to 7 days (given date \pm 3 days). Notably, for some dates no time averaging is necessary to determine a PV-gradient maximum.

We apply an additional constraint to exclude the subtropical jet from the calculation, which generally shows much larger PV-gradient values than the anticyclone transport barrier. Empirically, for the summer 2011 a PV-limit of 5 PVU reliably separates the monsoon transport barrier from the subtropical jet at $380 \mathrm{~K}$, as illustrated in Fig. 5b for 6 July. A physical motivation for this constraint can be deduced from the horizontal circulation (also averaged over \pm 1 day, see Fig. 7), as described in the following. Necessarily, the anticyclone transport barrier is located within the region of anticyclonic motion (negative relative vorticity), and hence in the equivalent latitude range where the circulation decreases when moving away from the anticyclone center (hence, with decreasing monsoon equivalent latitude). Consequently, the PV-gradient maximum of the anticyclone transport barrier needs to be located at equivalent latitudes larger than the minimum circulation (4.8 PVU in Fig. 7). This circulation constraint generally excludes the subtropical jet from the transport barrier calculation. For simplicity, we use $5 \mathrm{PVU}$ as an upper PV-limit for the transport barrier calculation at $380 \mathrm{~K}$ in the following, which is a good approximation of the circulation minimum. Note in addition that the second derivative of the circulation with respect to equivalent latitude $\partial^{2} \Gamma / \partial \phi_{\text {eq }}^{2}$ is related to the first derivative of PV (see Eq. 2). Therefore, the transport barrier related to the local maximum in the PV gradient can be approximated by the local maximum in the second derivative of $\Gamma$ (see Fig. 7, bottom), providing a consistency check of our procedure.

A necessary condition for the transport barrier criterion to hold is the existence of a strong PV anomaly. Therefore, the applicability is restricted to a shallow layer around $380 \mathrm{~K}$ (see Fig. 1). Figure 8 compares PV and its gradient with respect to monsoon equivalent latitude at different levels for 6 July 2011 ( \pm 1 day). The PV-gradient based transport barrier turns out to be clearest at the $380 \mathrm{~K}$ level, still detectable at 370 and $390 \mathrm{~K}$, but becomes undetectable below $(360 \mathrm{~K})$ and above $(400 \mathrm{~K})$. Strongest PV gradients at $380 \mathrm{~K}$ emerge not only for the 6 July, but during the whole summer (not shown). Note 
(a)
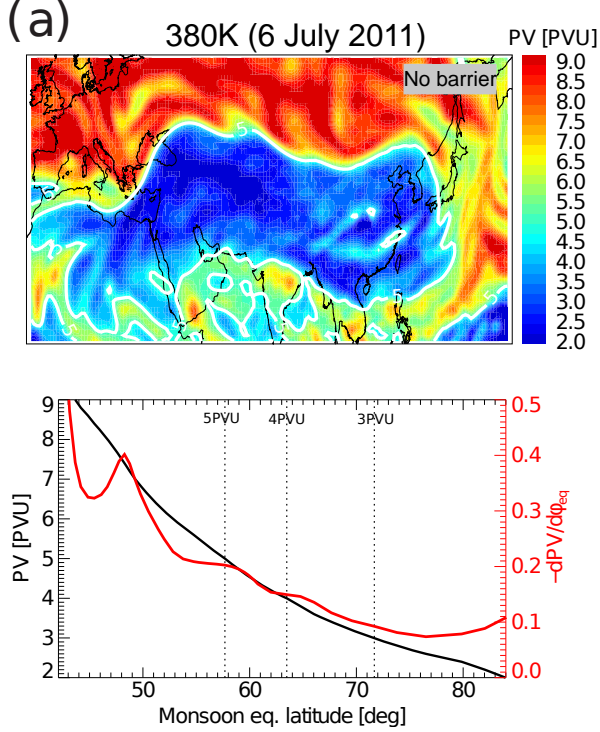

(b) 380K (6 July $2011+/-1$ day) PV [PVU]
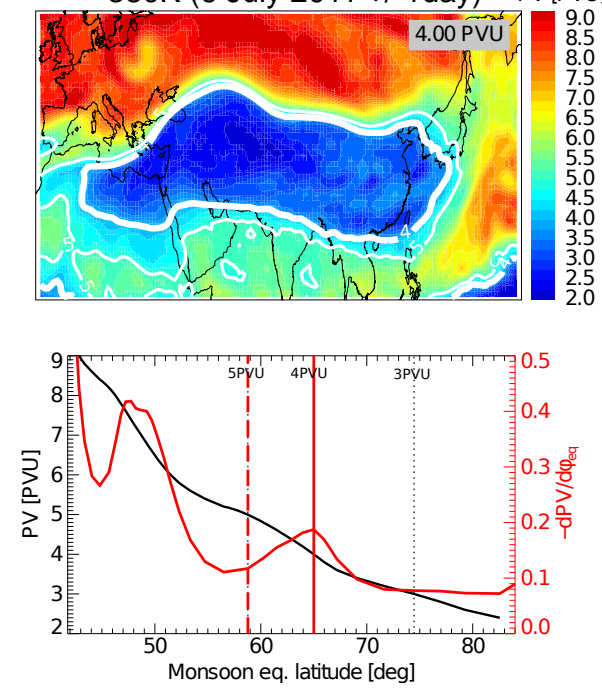

Figure 5. (a) Potential vorticity map at $380 \mathrm{~K}$ on 6 July 2011, in the Asian monsoon region between $10-60^{\circ} \mathrm{N}$ and $10^{\circ} \mathrm{W}-160^{\circ} \mathrm{E}$ (upper panel), and PV as a function of the monsoon centered equivalent latitude (lower panel). Monsoon equivalent latitude $\phi_{\mathrm{eq}}$ is calculated from the area within PV contours (see text). Shown is PV $\left(\phi_{\text {eq }}\right)$ (black) together with the respective PV gradient $\partial \mathrm{PV} / \partial \phi_{\mathrm{eq}}$ (red). Low PV and large $\phi_{\text {eq }}$ indicate the anticyclone center. (b) Same as panel (a) but for the PV-field averaged between 5 and 7 July 2011 . The anticyclone transport barrier, deduced from a local maximum in the PV gradient (see text), is shown as white thick contours (upper panels) and red solid vertical lines (lower panels), respectively. White thin contours (upper panels) and red dashed lines (lower panels) show 5 PVU. Black dashed lines (lower panels) highlight particular PV values. The PV-value of the barrier is given in the grey box.

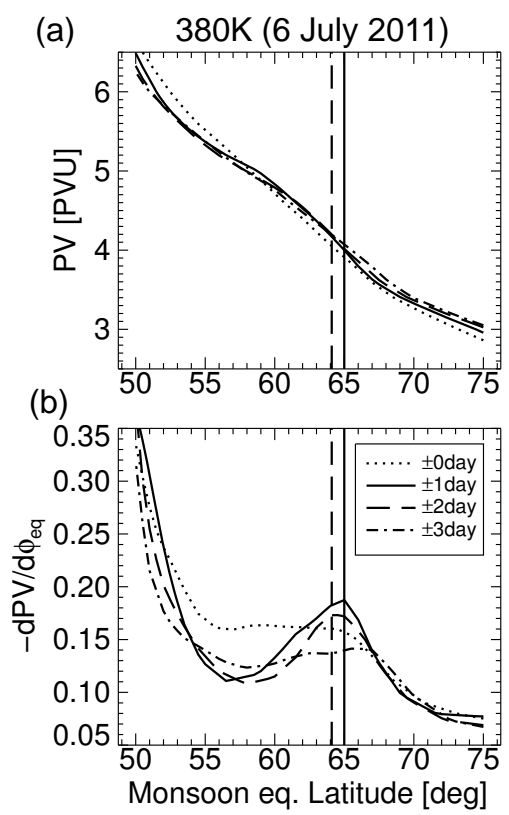

Figure 6. (a) Potential vorticity with respect to monsoon centered equivalent latitude on the $380 \mathrm{~K}$ isentrope, with the PV field averaged over different periods centered around 6 July 2011. (b) The corresponding gradients of PV with respect to equivalent latitude. Vertical lines show the PV-gradient maximum. that the corresponding PV values change between different levels, due to the strong dependence of PV on altitude. At levels of the subtropical jet core around $360 \mathrm{~K}$, the strong jet to the north of the monsoon masks the existence of the anticyclone transport barrier (Garny and Randel, 2013).

The tropopause within the monsoon is located at particularly high altitudes (see Fig. 1). Compared to the zonal mean, the tropopause is upward bulging in the monsoon anticyclone by about $20 \mathrm{~K}$ potential temperature (Fig. 1). Therefore, the detectable PV-gradient-based transport barrier around $380 \mathrm{~K}$ is likely related to the tropopause, with air masses inside the anticyclone being tropospheric and surrounding air masses stratospheric. Consequently, the diagnosed transport barrier can also be interpreted as a PV-based tropopause definition. Although enhanced PV gradients as a measure for confinement of air are detectable only within a shallow layer around the tropopause, the transport processes in the Asian monsoon occur throughout a thick layer from the surface to the lower stratosphere. As pointed out by Randel and Park (2006), the anticyclone at upper levels is strongly related to convective variability below.

To summarize, the minimum circulation (largest negative circulation values at approximately $5 \mathrm{PVU}$ ) defines the anticyclone boundary. The anticyclone transport barrier is then calculated from the time-averaged PV field as the maximum $\mathrm{PV}$ gradient at PV values smaller than $5 \mathrm{PVU}$. The procedure is illustrated in Fig. 9, and generally results in a well-defined PV-value (e.g., 4 PVU for 6 July 2011, see Fig. 5b) charac- 

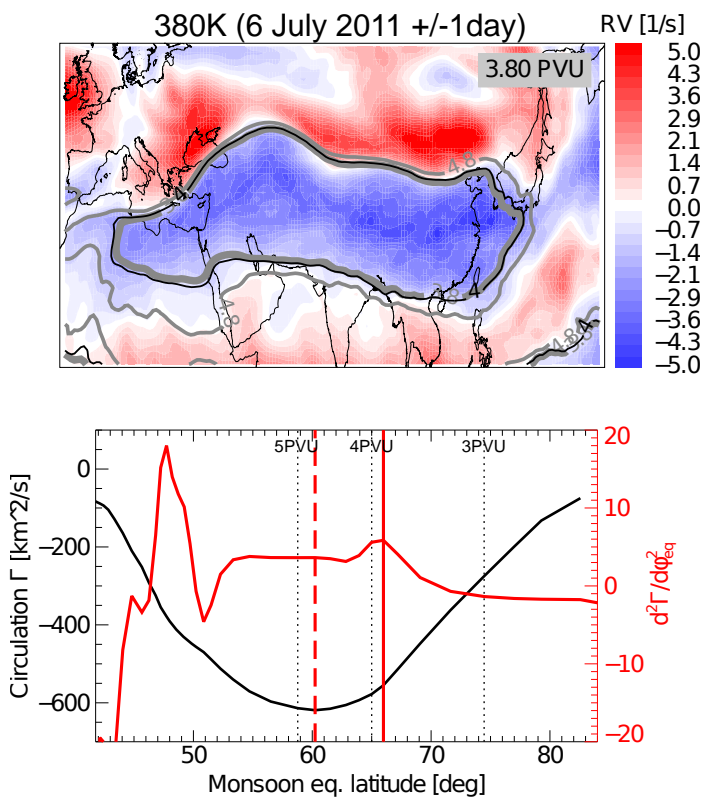

Figure 7. Relative vorticity map at $380 \mathrm{~K}$, in the Asian monsoon region between $10-60^{\circ} \mathrm{N}$ and $10^{\circ} \mathrm{W}-160^{\circ} \mathrm{E}$ averaged over 5-7 July 2011 (upper panel). The lower panel shows the horizontal circulation (calculated from area-integrated relative vorticity) as function of the monsoon centered equivalent latitude (black) and the respective second derivative (red). PV-values corresponding to the minimum circulation are shown as thin grey contour (upper panel) and red dashed line (lower), and PV-values corresponding to the maximum in the second derivative of the circulation as thick grey contour (upper) and red solid line (lower). The black contour (upper panel) shows the transport barrier PV deduced from the maximum PV-gradient, for comparison. (See text for further details).

terizing the transport barrier for the Asian monsoon anticyclone for most days between about mid-June and mid-August 2011. For some days during the summer season, however, no clear maximum emerges in the PV-gradient even after averaging over a few days (see also Fig. 12).

\section{PV-based transport barrier and relation to trace gases}

To investigate whether the diagnosed transport barrier is physically meaningful, in the sense of separating air masses of different chemical characteristics, we compare it to simulated $\mathrm{CO}$ in the Asian monsoon region. Figure 10 shows PV and $\mathrm{CO}$ maps at $380 \mathrm{~K}$ for the $6,9,12,15,18$ and 21 July 2011, overlaid with the PV contours of the transport barrier (thick white), as deduced for each date following the procedure described in Sect. 4. First, the barrier calculated from the time-averaged fields results in reasonable PV values also when compared to the instantaneous PV maps on the particular days. Second, in the $\mathrm{CO}$ distributions the diagnosed
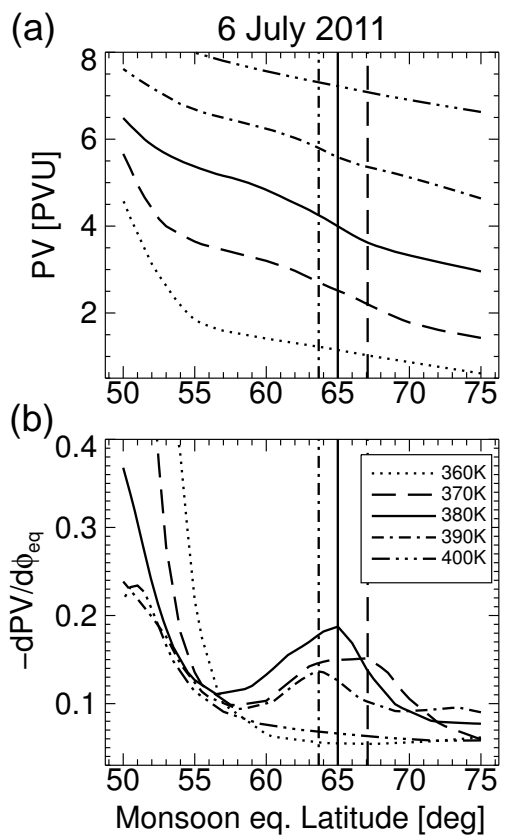

Figure 8. (a) Potential vorticity with respect to monsoon centered equivalent latitude for 6 July 2011 (calculated from the 5-7 July average), on different levels (360, 370, 380, 390, $400 \mathrm{~K}$ isentropes). (b) The corresponding PV-gradients with respect to equivalent latitude. Vertical lines show the gradient maxima (transport barriers).

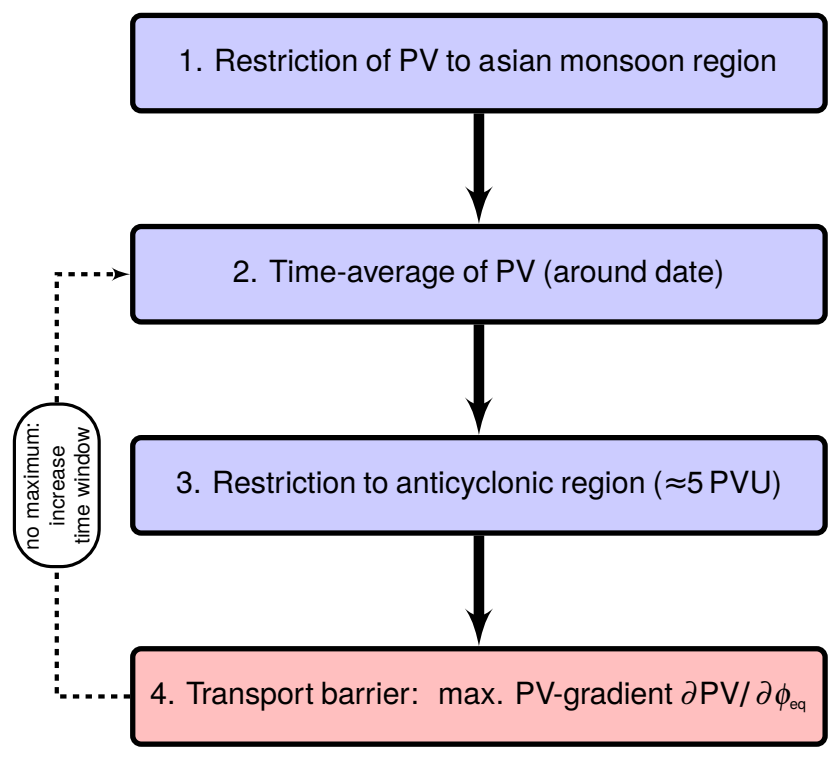

Figure 9. Method to localize the PV-based transport barrier in the Asian monsoon anticyclone (at $380 \mathrm{~K}$ ), summarized in four steps.

barrier separates the high mixing ratios in the center of the anticyclone from the lower values around.

The sequence of plots in Fig. 10 illustrates the large variability of the anticyclone, with frequent shedding of smaller scale eddies (9 July) and even splits of the anticyclone 

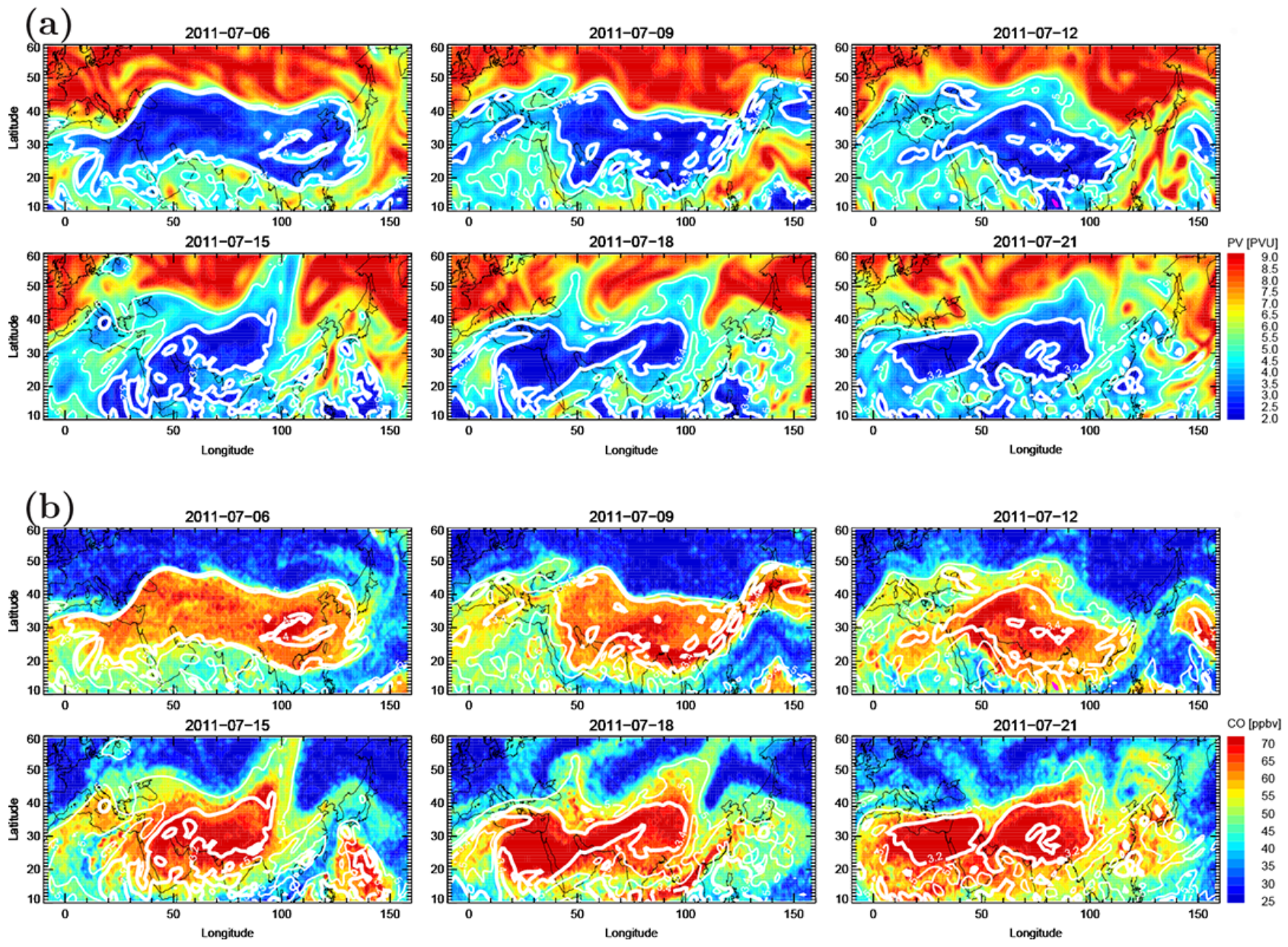

Figure 10. (a) Potential vorticity maps at $380 \mathrm{~K}$ on $6,9,12,15,18$, and 21 July 2011. The thick white contour shows the calculated anticyclone transport barrier (maximum PV gradient), the thin white contour 5 PVU. (b) Maps of CO from CLaMS on the same days, with PV-based transport barrier included as white contours.

(21 July). Also for days of particularly large variability the diagnosed barrier separates well the core region of the anticyclone, characterized by high $\mathrm{CO}$ mixing ratios, from its surroundings. Even the shedding of the smaller eddy and the vortex split are reflected in the transport barrier. It should be further noted that the agreement between PV and CO is not perfect and that high CO mixing ratios may extend outside the PV contour (e.g., on 18 July at the northeastern edge of the anticyclone), a potential indication of the leakiness of the anticyclone transport barrier.

To investigate more quantitatively to what degree the transport barrier deduced from $\mathrm{PV}$ is reflected in the $\mathrm{CO}$ distribution, we apply the barrier calculation to $\mathrm{CO}$, exemplarily for 6 July 2011. Therefore, we restrict the CO field to the monsoon region, average over \pm 1 days (5-7 July 2011), transform to PV-based monsoon centered equivalent latitude $\phi_{\mathrm{eq}}$, restrict to the anticyclonic region and calculate the PV-value of the maximum $\mathrm{CO}$ gradient $\partial \mathrm{CO} / \partial \phi_{\text {eq }}$. Figure 11a shows that a clear $\mathrm{CO}$-gradient maximum emerges around $65^{\circ}$, equivalent to a PV value of $4 \mathrm{PVU}$, in agreement with the transport barrier deduced from the maximum PV-gradient. Likewise, distributions of simulated ozone and mean age of air reflect the PV-based transport barrier within the Asian monsoon region (Fig. 11b, c).

The PV-gradient based transport barrier for the Asian monsoon anticyclone has been calculated for all days between 20 June and 20 August 2011. Before this period and afterwards, almost no barrier could be found. CLaMS CO fields show trace gas confinement inside the anticyclone from mid-June 2011 onwards, but obviously the transport barrier during this early phase is not strong enough to be detectable by our method. Likewise, following the main monsoon season first the PV-gradient maximum vanishes (by mid-end of August) but trace gas anomalies remain for a few weeks until mid-September. Hence, the degree of confinement inside the anticyclone is strong enough for a PV-gradient maximum to be detected only during the main monsoon season. 
(a)
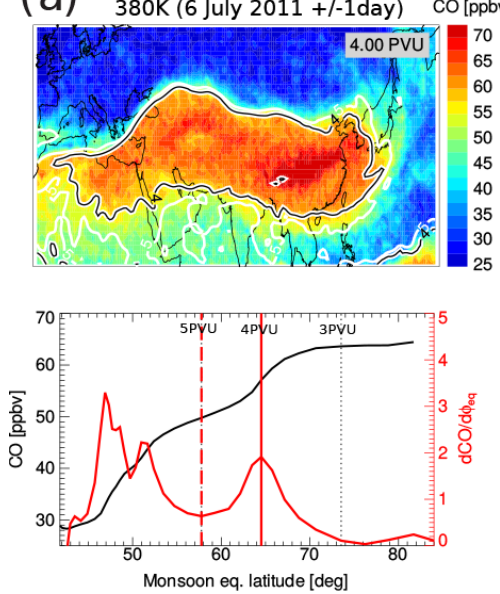

(b) 380K (6 July $2011+/-1$ day) 03 [ppbv]
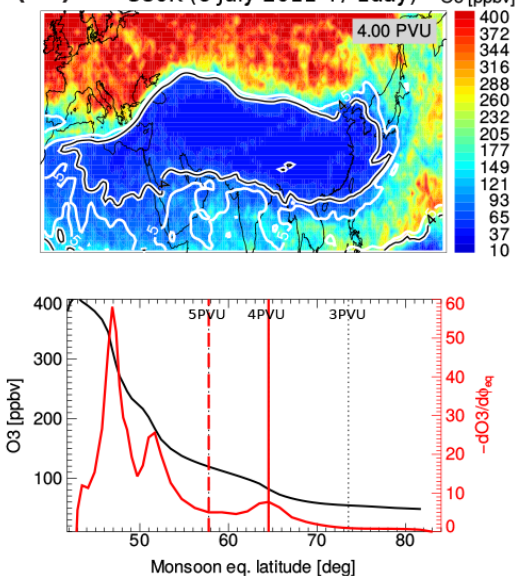

(c)
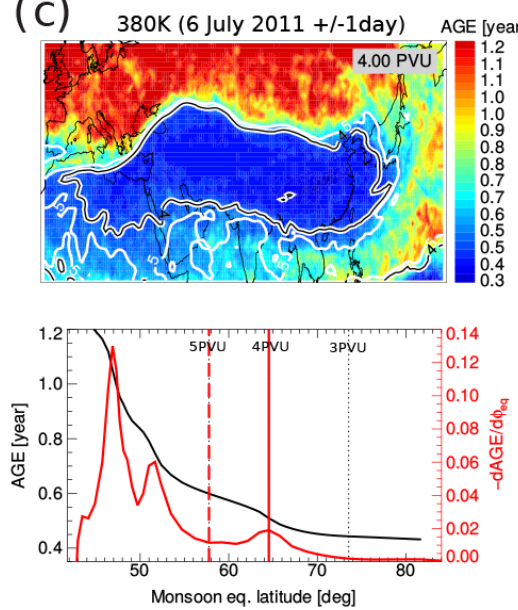

Figure 11. (a) Map of CO from CLaMS on the $380 \mathrm{~K}$ isentrope, with the thick white contour showing the PV-value of maximum COgradient, the black contour showing the PV-value of maximum PV-gradient (thin white line shows 5 PVU), averaged between 5 and 7 July 2011 at $380 \mathrm{~K}$. The bottom panel shows CO from CLaMS vs. monsoon centered equivalent latitude (black), and the respective gradient (red). (b) Same for ozone from CLaMS, and (c) for mean age from CLaMS. (The PV values of the maximum gradient are given in the upper panels.)

Figure 12 (top) shows the evolution of the PV-gradient at $380 \mathrm{~K}$ over the summer season. Although the gradient maximum related to the anticyclone barrier appears weaker during some periods, it shows smooth subseasonal variability, with higher PV values (around 4 PVU) at the beginning of July and the beginning of August and lower PV values (around 3.2 PVU) in mid July and mid August. Significant subseasonal dynamic variability of the Asian monsoon, occurring with a frequency of about 30 days, has been recently noted by Garny and Randel (2013). Only for a few days (end of June and beginning of August) no transport barrier could be deduced because no clear maximum in the PV gradient emerged.

The evolution of the gradients of $\mathrm{CO}$, ozone and mean age over the summer (Fig. 12b-d) consistently shows a local maximum throughout most of the season, coinciding well with the PV-based transport barrier. However, by the end of July and after 15 August, there is additional structure in the trace gas distributions at PV values above $4 \mathrm{PVU}$, which is not reflected in the PV gradients. During these periods, the maximum trace gas gradients are located at higher PV values than the PV-based transport barrier. To what degree the strength of the anticyclone transport barrier can be related to convection (which increases the area of low PV values, see Randel and Park, 2006) and to other dynamical processes is beyond the scope of this paper and needs to be further studied.

At $380 \mathrm{~K}$, the PV value at the determined transport barrier is generally found between about 3 and 4 PVU, and shows intraseasonal variability. The mean PV value of the transport barrier over the summer 2011 is 3.6 PVU (at $380 \mathrm{~K}$ ), in very good agreement with the mean PV of the related CO-gradient
Table 1. Transport barrier PV values for the Asian monsoon anticyclone at $380 \mathrm{~K}$ calculated from maximum PV and CO gradients and maximum-minimum ranges for the years 2011-2013 (averages over all dates between 20 June and 20 August of each year where the transport barrier criterion holds).

\begin{tabular}{lrrr}
\hline & 2011 & 2012 & 2013 \\
\hline PV-barrier/PVU & $3.6(3.0-4.4)$ & $3.8(2.6-4.4)$ & $3.5(2.6-4.4)$ \\
CO-barrier/PVU & $3.7(3.2-4.4)$ & $3.7(2.4-4.6)$ & $3.6(2.6-4.2)$ \\
\hline
\end{tabular}

maximum (Table 1). We calculated the transport barrier PV values also for summers 2012 and 2013 (see Table 1) and found some weak interannual variability which needs to be further investigated. Note that the interannual variability and model-projected future changes of the Asian monsoon anticyclone are largely uncertain, hitherto (e.g., Kunze et al., 2010)

\section{Anticyclone location probability}

The location probability for the region enclosed by the transport barrier ("anticyclone core region", in the following) is shown in Fig. 13. Presented is the local frequency of occurrence for PV values lower than the anticyclone barrier value, in units of percentage of days during summer 2011 (20 June to 20 August 2011). Clearly, the largest probability of being located inside the anticyclone core occurs around $70^{\circ} \mathrm{E} / 30^{\circ} \mathrm{N}$ (above $80 \%$ of the considered days). The whole region between about $25-40^{\circ} \mathrm{N}$ and $20-100^{\circ} \mathrm{E}$ is located within the anticyclone core for more than $50 \%$ of the days. Note that the anticyclone location probability may show sig- 

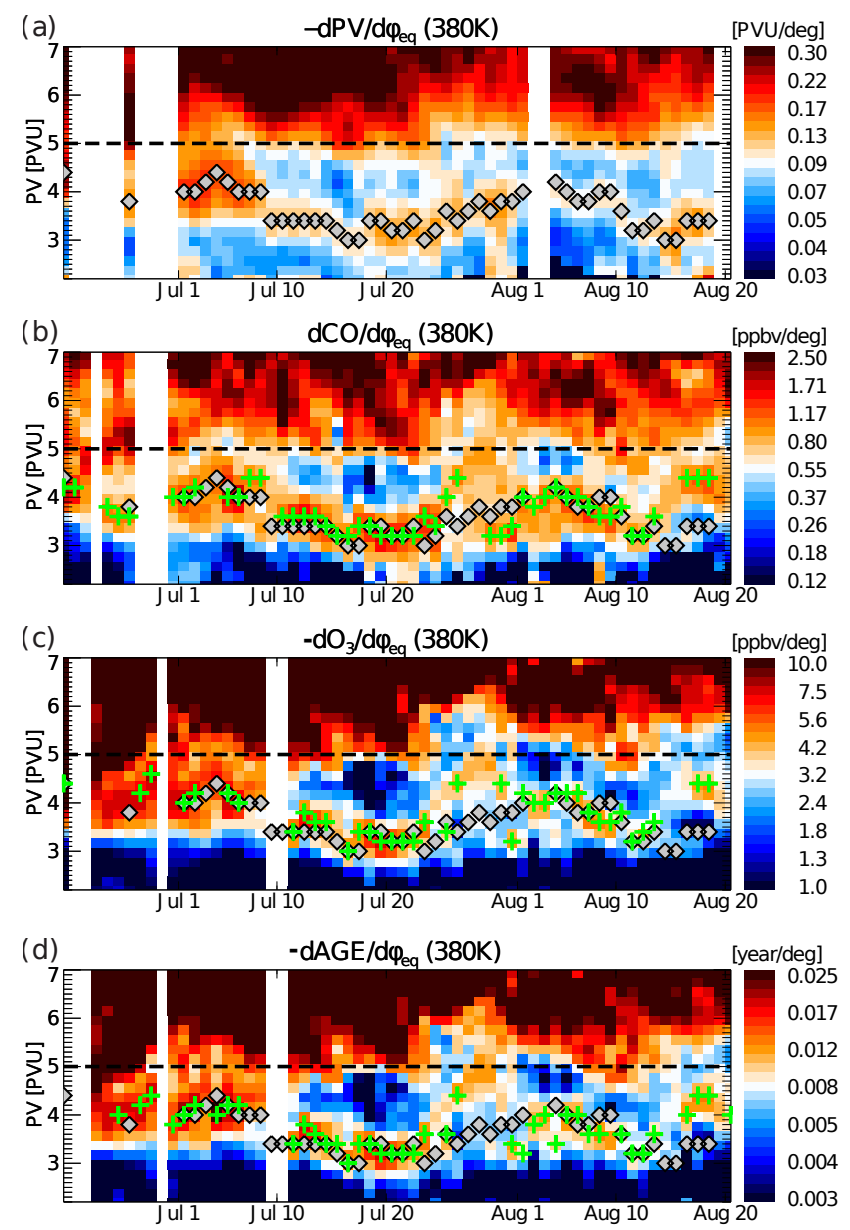

Figure 12. (a) Time evolution of the gradient of PV with respect to monsoon centered equivalent latitude $\phi_{\mathrm{eq}}$ as a function of PV for the period 20 June to 20 August 2011 at $380 \mathrm{~K}$ (note the logarithmic color scale). The same is shown for panels (b) $\mathrm{CO}$, (c) $\mathrm{O}_{3}$, and (d) mean age. Symbols show the PV-gradient maximum (grey diamonds), and the CO-gradient maximum (green crosses). The dashed line highlights 5 PVU. Dates without a clear gradient maximum are left white.

nificant interannual variability (e.g., a broader distribution in longitude in 2012 compared to 2011 and 2013) which needs to be further studied.

Zhang et al. (2002) and Yan et al. (2011) found an enhanced probability for the anticyclone center (estimated as geopotential height maximum) to occur at longitudes of the Tibetan (around $70-100^{\circ} \mathrm{E}$ ) and the Iranian (around 45$65^{\circ} \mathrm{E}$ ) plateaus, resulting in a bimodal longitude occurrence frequency. Figure 13a shows no enhanced probability for the anticyclone core region to be located in these two regions. However, if projected onto the longitude axis, the anticyclone location probability indicates two weak maxima (Fig. 13a/bottom), located at about 55 and $85^{\circ} \mathrm{E}$. To what degree the bimodality in the longitudinal geopotential height maximum distribution found by Zhang et al. (2002) has a (a) Anticyclone core location occurrence (380K) \%/days
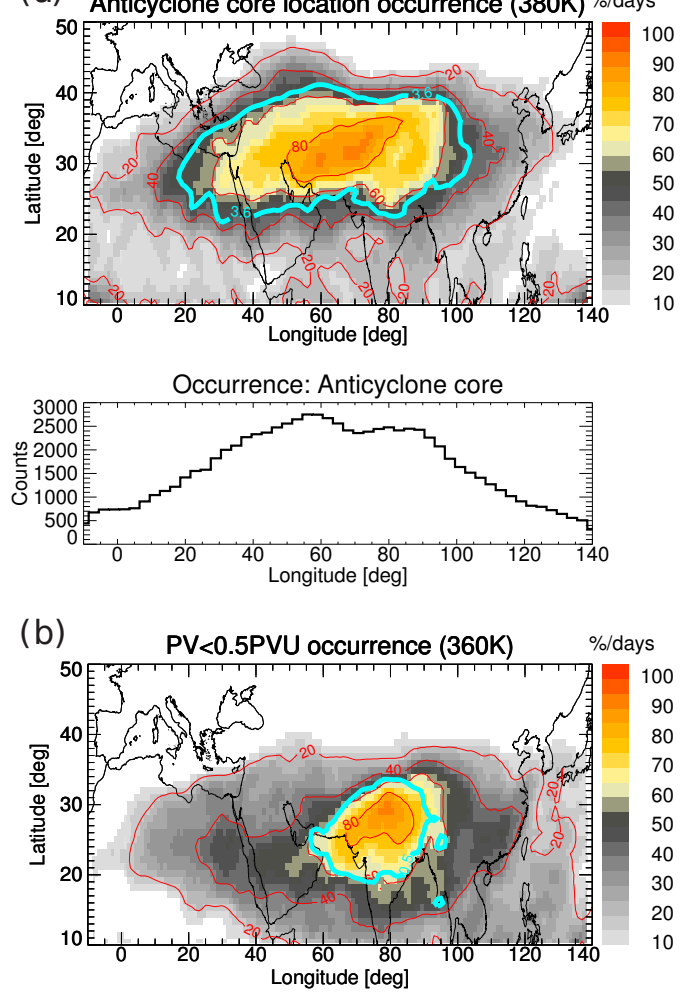

Figure 13. (a) Occurrence frequency of the Asian monsoon anticyclone at $380 \mathrm{~K}$ (in percentage of days) for the period between 20 June and 20 August 2011, calculated from the area covered by PV values lower than the anticyclone transport barrier. Red contours show selected percentage values $(20,40,60,80 \%)$, the thick cyan contour shows the average PV value of the barrier in the average PV field (average over the period considered). The bottom panel shows the projection of anticyclone occurrence frequency onto the longitude axis (bin size $2.5^{\circ}$ ). (b) Occurrence frequency for PV values below $0.5 \mathrm{PVU}$ at $360 \mathrm{~K}$ isentrope, for the same period (cyan contour shows $0.5 \mathrm{PVU}$ in the average PV field).

physical basis, originating from enhanced occurrence probability in particular geographic regions, or is an artifact of the projection needs to be further studied.

Note that the large zonal extent of the anticyclone occurrence probability at $380 \mathrm{~K}$ in Fig. 13a is related to frequent eddy shedding events, with the above analysis not distinguishing between the main anticyclone and westward and eastward traveling eddies. Also note that at lower levels (e.g., at $360 \mathrm{~K}$ in Fig. 13b) the region of lowest PV values is more confined and located further eastward and southward above the Tibetan plateau and Northern India, within the region of the vertical conduit for upward transport in the monsoon proposed by Bergman et al. (2013). 


\section{Discussion}

Recently, Bergman et al. (2013) showed evidence for upward transport in the Asian monsoon occurring in a vertical conduit separated from the main anticyclone. Hence, it is not the anticyclone itself but this conduit which defines the most efficient pathway of polluted surface air to higher altitudes. However, as the air is released from the conduit at greater altitudes, it stays confined and chemically isolated, at least to some degree, inside the anticyclone, as shown from trace gas observations (e.g., Park et al., 2007, 2008). Therefore, a complete understanding of pollution transport from the boundary layer into the stratosphere requires understanding of the confinement inside the upper level anticyclone.

In this paper, we investigated to what extent meteorological fields and trace gas distributions reflect the existence of a barrier to (quasi-) horizontal transport along isentropic surfaces in the Asian monsoon anticyclone. We refined the methodology developed for the polar vortex by additional constraints (e.g., time averaging, restriction to anticyclone) and found a secondary maximum besides the subtropical jet maximum in the gradient of potential vorticity with respect to a monsoon-centered equivalent latitude (related to the area enclosed within PV contours). We interpreted this $\mathrm{PV}$-gradient maximum as the transport barrier in the monsoon anticyclone. This PV-gradient based transport barrier for the monsoon is deducible in a layer around the tropopause (around $380 \mathrm{~K}$ ) for most days between mid-June to midAugust 2011.

However, the PV-gradient based transport barrier, and hence the related confinement of air masses, in the monsoon anticyclone appears much weaker than the transport barrier at the edge of the polar vortex (e.g., Nash et al., 1996) and also weaker than the barrier at the subtropical jet (see Kunz et al., 2011), likely related to the large dynamic variability of the monsoon anticyclone. Daily maps of the anticyclone show large displacements in east-west direction, shedding of smaller-scale eddies and even splits (Fig. 10), frequently causing air masses to be torn out of the anticyclone. In particular the strong diabatic heating related to deep convection over South Asia affects the anticyclonic monsoon circulation (Randel and Park, 2006) and potentially the strength of the transport barrier (e.g., Fig. 12). Hence, the anticyclone transport barrier turns out to be leaky, allowing cross-barrier transport to some degree, and the maximum PV gradient is better interpreted as a measure of the degree of confinement of the air masses than describing a rigid barrier to the flow. Nonetheless, for the sake of clear terminology we use the term "barrier" throughout this study.

Despite the leakiness of the barrier, diagnosing the corresponding PV-value offers a method for separating the core of the monsoon anticyclone from its surroundings. Hence, the size of the anticyclone core may be determined and air masses may be appropriately tagged. This offers new opportunities for model studies of Asian monsoon impact and for

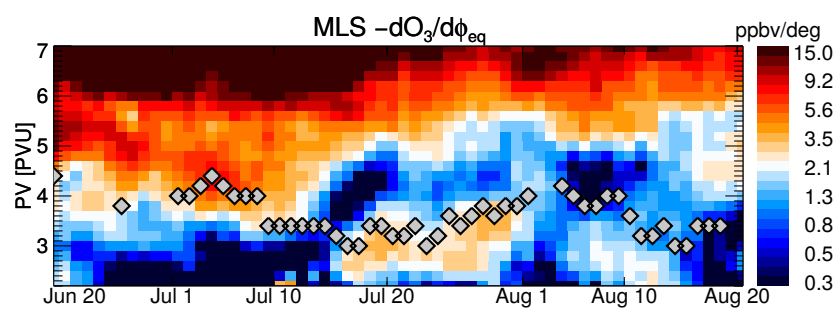

Figure 14. Time evolution of the gradient of ozone from MLS with respect to monsoon equivalent latitude (based on ERA-Interim PV) for June-August 2011 at $380 \mathrm{~K}$ (note the logarithmic color scale). At each date, MLS measurements from 2 days before to 2 days later have been collected, to yield a sufficient coverage of the monsoon region. Grey symbols show the PV-gradient maximum.

evaluation of measurements from the monsoon region. The degree of confinement inside the anticyclone further determines how effectively air masses from the anticyclone core mix with air from the anticyclone edge. Air masses from different transport pathways may be injected into different regions of the anticyclone (e.g., into the core by convection and upwelling within the conduit (Bergman et al., 2013), or into the anticyclone edge by typhoons over Southeast Asia (Vogel et al., 2014)). Therefore, chemical reactions and lifetimes of short-lived species, and the effectivity of pollution transport into the stratosphere will depend on the degree of confinement.

The smooth evolution of the anticyclone transport barrier over the season (Fig. 12) enhances our confidence in its relation to a physical mechanism. Furthermore, enhanced gradients in CLaMS simulated trace gas distributions $\left(\mathrm{CO}, \mathrm{O}_{3}\right.$ and mean age) clearly demonstrate the existence of the PVgradient based transport barrier. These enhanced trace gas gradients are reflected in corresponding minima in mixing ratio PDFs (see Appendix). However, a proper validation of the meaningfulness of the diagnosed transport barrier can only be achieved by comparison to trace gas measurements. Figure 14 compares the gradient (with respect to monsoon equivalent latitude) of MLS observed ozone in the monsoon region to the PV-based transport barrier (grey symbols), similarly to Fig. 3 but for the entire season. Maximum ozone and PV gradients agree well during the beginning of July and the middle to end of July. During mid-August, the PV-based barrier is located at higher PV values, but shows a similar temporal evolution as the maximum ozone gradient.

The disagreements between the model and MLS are not unexpected, mainly because of the different resolutions (e.g., vertical resolution around the tropopause of about $400 \mathrm{~m}$ in CLaMS vs. about $3 \mathrm{~km}$ in MLS). Nonetheless, MLS ozone shows enhanced gradients coinciding with the PV value of the transport barrier over several days, providing further confidence in the PV-based anticyclone transport barrier. Further analysis of observations of higher resolution (e.g., in situ observations) would be desirable. 


\section{Conclusions}

As shown by anomalies in several trace gas observations, the air inside the Asian monsoon anticyclone appears, at least to some degree, confined and isolated from its surroundings. Diagnosing the related transport barrier offers new opportunities for quantifying the transport of tropospheric source gases into the UTLS (e.g., determining anticyclone size, tagging air masses). In this paper, we showed that the potential vorticity field reflects the existence of a barrier to horizontal transport between the anticyclone and its surroundings. Although the detection of the transport barrier is hampered by the large dynamic variability of the anticyclone and the proximity to the subtropical jet, a refined PV-gradient criterion may be used to deduce the barrier within the Asian monsoon anticyclone, in a layer around $380 \mathrm{~K}$. Therefore, we refined the criterion developed for the polar vortex (e.g., Nash et al., 1996) and determined the anticyclone transport barrier from the PV-gradient maximum, after restricting the PV field to the monsoon region and averaging over a time window around the given date (summarized in Fig. 9). Comparison to trace gas distributions shows that the $\mathrm{PV}$-gradient based transport barrier is meaningful in the sense of separating air masses of different chemical characteristics. The deduced PV values (e.g., 3.6 on average for 2011 at $380 \mathrm{~K}$ ) offer a physically motivated criterion to separate the inner core of the anticyclone from the surrounding region, crucial for the interpretation of trace gas observations and for model studies. 


\section{Appendix A: Transport barrier from trace gas mixing ratio $P D F$}

To further increase the confidence in the existence of the PVgradient transport barrier, we deduce the anticyclone transport barrier also from simulated $\mathrm{CO}$ using a different methodology based on probability density functions (PDF) and show its consistency with the PV-based results (for a review of the PDF method, see Sparling, 2000). Therefore, we calculate the PDF of CLaMS simulated $\mathrm{CO}$ mixing ratios in the Asian monsoon region $\left(10-60^{\circ} \mathrm{N}, 10^{\circ} \mathrm{W}-160^{\circ} \mathrm{E}\right)$ for a \pm 1 day time window around 6 July 2011 (Fig. A1). The PDF was constructed after assigning the appropriate area-weighting to the data points. Mean CO monotonically decreases with increasing PV, with high CO inside the monsoon (coinciding with low PV) and low $\mathrm{CO}$ outside. Minima in the mixing ratio PDF indicate regions of suppressed horizontal transport (Sparling, 2000).

The PDF in Fig. A1 shows one minimum at $\mathrm{CO}$ mixing ratios around 35-40 ppbv, related to the subtropical jet, and a secondary minimum around $55 \mathrm{ppbv}$, related to the transport barrier inside the Asian monsoon anticyclone. From the PDF of $\mathrm{PV}$ values corresponding to $\mathrm{CO}$ mixing ratios around the minimum, we find a corresponding PV value of 4.1 PVU, in good agreement to the $4 \mathrm{PVU}$ emerging from the PV-gradient maximum (Fig. A1/bottom).

For 6 July, the CO PDF shows the anticyclone transport barrier even for the instantaneous distribution, without averaging over \pm 1 days (not shown). Note that the PDF approach is related to the PV-gradient method (e.g., Neu et al., 2003; Palazzi et al., 2011).

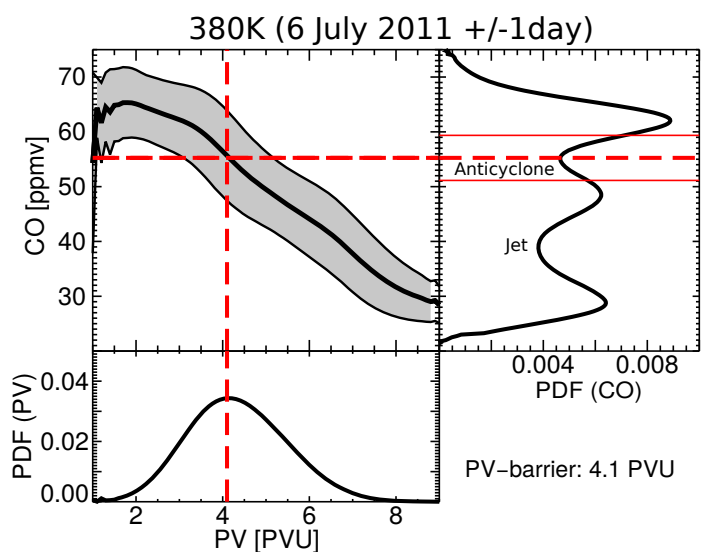

Figure A1. Asian monsoon transport barrier at $380 \mathrm{~K}$ on 6 July 2011 from the CO mixing ratio PDF. The main panel (upper left) shows CLaMS CO (monsoon region average, 5-7 July time average) vs. PV with one standard deviation as grey shading. The upper right panel shows the corresponding mixing ratio PDF with the monsoon transport barrier highlighted as red dashed line. The lower panel shows the PDF of PV-values around the barrier (between the thin red lines in the upper right panel). (See text for further details.)

Still, the comparison between the two methods shows the robustness of the deduced transport barrier. Similarly to the PVbased approach, the PDF approach fails in locating a transport barrier at several days during summer. The use of mixing ratio PDF's offers a simple method to deduce the anticyclone transport barrier from satellite observations. 
Acknowledgements. We thank Bernard Legras for advice, Nicole Thomas for programming support and the ECWMF for providing reanalysis data. We further thank Gloria Manney and two anonymous reviewers for their helpful and constructive comments on the manuscript. F. Ploeger was funded by an HGF postdoc grant, and further thanks go to the HGF for supporting a research stay at the Laboratoire de Météorologie Dynamique of the École Normale Supérieure in Paris during which parts of this work had been carried out.

The article processing charges for this open-access publication were covered by a Research

Centre of the Helmholtz Association.

Edited by: T. J. Dunkerton

\section{References}

Abalos, M., Ploeger, F., Konopka, P., Randel, W. J., and Serrano, E.: Ozone seasonality above the tropical tropopause: reconciling the Eulerian and Lagrangian perspectives of transport processes, Atmos. Chem. Phys., 13, 10787-10794, doi:10.5194/acp13-10787-2013, 2013.

Bergman, J. W., Jensen, E. J., Pfister, L., and Yang, Q.: Seasonal differences of vertical-transport efficiency in the tropical tropopause layer: On the interplay between tropical deep convection, largescale vertical ascent, and horizontal circulations, J. Geophys. Res., 117, D05302, doi:10.1029/2011JD016992, 2012.

Bergman, J. W., Fierli, F., Jensen, E. J., Honomichl, S., and Pan, L. L.: Boundary layer sources for the Asian anticyclone: Regional contributions to a vertical conduit, J. Geophys. Res., 118, 2560-2575, 2013.

Bian, J., Pan, L. L., Paulik, L., Vömel, H., Chen, H., and Lu, D.: In situ water vapor and ozone measurements in Lhasa and Kunming during the Asian summer monsoon, Geophys. Res. Lett., 39, L19808, doi:10.1029/2012GL052996, 2012.

Butchart, N. and Remsberg, E. E.: The area of the stratospheric polar vortex as a diagnostic for tracer transport on an isentropic surface, J. Atmos. Sci., 43, 1319-1339, 1986.

Dee, D. P., Uppala, S. M., Simmons, A. J., Berrisford, P., Poli, P., Kobayashi, S., Andrae, U., Balmaseda, M. A., Balsamo, G., Bauer, P., Bechtold, P., Beljaars, A. C. M., van de Berg, L., Bidlot, J., Bormann, N., Delsol, C., Dragani, R., Fuentes, M., Geer, A. J., Haimberger, L., Healy, S. B., Hersbach, H., Holm, E. V., Isaksen, L., Kallberg, P., Kohler, M., Matricardi, M., McNally, A. P., Monge-Sanz, B. M., Morcrette, J. J., Park, B. K., Peubey, C., de Rosnay, P., Tavolato, C., Thepaut, J. N., and Vitart, F.: The ERA-Interim reanalysis: configuration and performance of the data assimilation system, Q. J. Roy. Meteor. Soc., 137, 553-597, doi:10.1002/qj.828, 2011.

Fueglistaler, S., Dessler, A. E., Dunkerton, T. J., Folkins, I., Fu, Q., and Mote, P. W.: Tropical Tropopause layer, Rev. Geophys., 47, RG1004, doi:10.1029/2008RG000267, 2009.

Garny, H. and Randel, W. J.: Dynamic variability in the Asian monsoon anticyclone observed in potential vorticity and correlations with tracer distributions, J. Geophys. Res., 118, 13421-13433, 2013.
Gill, A. E.: Some simple solutions for heat-induced tropical circulation, Q. J. Roy. Meteor. Soc., 106, 447-462, 1980.

Holton, J. R.: An Introduction to Dynamic Meteorology, Academic Press, London, UK, 1992.

Hoor, P., Wernli, H., Hegglin, M. I., and Bönisch, H.: Transport timescales and tracer properties in the extratropical UTLS, Atmos. Chem. Phys., 10, 7929-7944, doi:10.5194/acp-10-79292010, 2010.

Hsu, C. J. and Plumb, R. A.: Non-axisymmetric thermally driven circulations and upper tropospheric monsoon dynamics, J. Atmos. Sci., 57, 1254-1276, 2000.

James, R., Bonazzola, M., Legras, B., Surbled, K., and Fueglistaler, S.: Water vapor transport and dehydration above convective outflow during Asian monsoon, Geophys. Res. Lett., 35, L20810, doi:10.1029/2008GL035441, 2008.

Konopka, P., Günther, G., Müller, R., dos Santos, F. H. S., Schiller, C., Ravegnani, F., Ulanovsky, A., Schlager, H., Volk, C. M., Viciani, S., Pan, L. L., McKenna, D.-S., and Riese, M.: Contribution of mixing to upward transport across the tropical tropopause layer (TTL), Atmos. Chem. Phys., 7, 3285-3308, doi:10.5194/acp-7-3285-2007, 2007.

Konopka, P., Grooß, J.-U., Günther, G., Ploeger, F., Pommrich, R., Müller, R., and Livesey, N.: Annual cycle of ozone at and above the tropical tropopause: observations versus simulations with the Chemical Lagrangian Model of the Stratosphere (CLaMS), Atmos. Chem. Phys., 10, 121-132, doi:10.5194/acp-10-121-2010, 2010.

Krishnamurti, T. N., Daggupaty, S. M., Fein, J., Kanamitsu, M., and Lee, J. D.: Tibetan high and upper tropospheric tropical circulation during Northern summer, B. Am. Meteorol. Soc., 54, 12341249, 1973.

Kunz, A., Konopka, P., Müller, R., and Pan, L. L.: Dynamical tropopause based on isentropic potential vorticity gradients, J. Geophys. Res., 116, D01110, 2011.

Kunze, M., Braesicke, P., Langematz, U., Stiller, G., Bekki, S., Brühl, C., Chipperfield, M., Dameris, M., Garcia, R., and Giorgetta, M.: Influences of the Indian summer monsoon on water vapor and ozone concentrations in the UTLS as simulated by chemistry-climate models, J. Climate, 23, 3525-3544, 2010.

Livesey, N. J., Filipiak, M. J., Froideveaux, L., Read, W. G., Lambert, A., Santee, M. L., Jiang, J. H., Pumphrey, H. C., Waters, J. W., Cofield, R. E., Cuddy, D. T., Daffer, W. H., Drouin, B. J., Fuller, R. A., Jarnot, R. F., Jiang, Y. B., Knosp, B. W., Li, Q. B., Perun, V. S., Schwartz, M. J., Snyder, W. J., Stek, P. C., Thurstans, R. P., Wagner, P. A., Avery, M., Browell, E. V., Cammas, J. P., Christensen, L. E., Diskin, G. S., Gao, R. S., Jost, H. J., Loewenstein, M., Lopez, J. D., Nedelec, P., Osterman, G. B., Sachse, G. W., and Webster, C. R.: Validation of Aura Microwave Limb Sounder $\mathrm{O}_{3}$ and $\mathrm{CO}$ observations in the upper troposphere and lower stratosphere, J. Geophys. Res., 113, D15S02, doi:10.1029/2007JD008805, 2008.

Manney, G. L., Zurek, R. W., Gelman, M. E., Miller, A. J., and Nagatani, R.: The anomalous Arctic lower stratospheric polar vortex of 1992-1993, Geophys. Res. Lett., 21, 2405-2408, 1994.

McKenna, D. S., Grooß, J.-U., Günther, G., Konopka, P., Müller, R., Carver, G., and Sasano, Y.: A new Chemical Lagrangian Model of the Stratosphere (CLaMS): 2. Formulation of chemistry scheme and initialization, J. Geophys. Res., 107, 4256, doi:10.1029/2000JD000113, 2002a. 
McKenna, D. S., Konopka, P., Grooß, J.-U., Günther, G., Müller, R., Spang, R., Offermann, D., and Orsolini, Y.: A new Chemical Lagrangian Model of the Stratosphere (CLaMS): 1. Formulation of advection and mixing, J. Geophys. Res., 107, 4309, doi:10.1029/2000JD000114, 2002b.

Nash, E. R., Newman, P. A., Rosenfield, J. E., and Schoeberl, M. R.: An objective determination of the polar vortex using Ertel's potential vorticity, J. Geophys. Res., 101, 9471-9478, 1996.

Neu, J. L., Sparling, L. C., and Plumb, R. A.: Variability of the subtropical "edges" in the stratosphere, J. Geophys. Res., 108, 4482, doi:10.1029/2002JD002706, 2003.

Palazzi, E., Fierli, F., Stiller, G. P., and Urban, J.: Probability density functions of long-lived tracer observations from satellite in the subtropical barrier region: data intercomparison, Atmos. Chem. Phys., 11, 10579-10598, doi:10.5194/acp-11-10579-2011, 2011.

Park, M., Randel, W. J., Gettelman, A., Massie, S. T., and Jiang, J. H.: Transport above the Asian summer monsoon anticyclone inferred from Aura Microwave Limb Sounder tracers, J. Geophys. Res., 112, D16309, doi:10.1029/2006JD008294, 2007.

Park, M., Randel, W. J., Emmons, L. K., Bernath, P. F., Walker, K. A., and Boone, C. D.: Chemical isolation in the Asian monsoon anticyclone observed in Atmospheric Chemistry Experiment (ACE-FTS) data, Atmos. Chem. Phys., 8, 757-764, doi:10.5194/acp-8-757-2008, 2008.

Ploeger, F., Konopka, P., Müller, R., Fueglistaler, S., Schmidt, T., Manners, J. C., Grooß, J.-U., Günther, G., Forster, P. M., and Riese, M.: Horizontal transport affecting trace gas seasonality in the Tropical Tropopause Layer TTL, J. Geophys. Res., 117, 09303, doi:10.1029/2011JD017267, 2012.

Ploeger, F., Günther, G., Konopka, P., Fueglistaler, S., Müller, R., Hoppe, C., Kunz, A., Spang, R., Grooß, J.-U., and Riese, M.: Horizontal water vapor transport in the lower stratosphere from subtropics to high latitudes during boreal summer, J. Geophys. Res., 118, 8111-8127, doi:10.1002/jgrd.50636, 2013.

Pommrich, R., Müller, R., Grooß, J.-U., Konopka, P., Ploeger, F., Vogel, B., Tao, M., Hoppe, C. M., Günther, G., Spelten, N., Hoffmann, L., Pumphrey, H.-C., Viciani, S., D’Amato, F., Volk, C. M., Hoor, P., Schlager, H., and Riese, M.: Tropical troposphere to stratosphere transport of carbon monoxide and long-lived trace species in the Chemical Lagrangian Model of the Stratosphere (CLaMS), Geosci. Model Dev., 7, 2895-2916, doi:10.5194/gmd7-2895-2014, 2014.
Popovich, J. M. and Plumb, R. A.: Eddy Shedding from the UpperTropospheric Asian Monsoon Anticyclone, J. Atmos. Sci., 58, 93-104, 2001.

Randel, W. J. and Park, M.: Deep convective influence on the Asian summer monsoon anticyclone and associated tracer variability observed with Atmospheric Infrared Sounder (AIRS), J. Geophys. Res., 111, D12314, doi:10.1029/2005JD006490, 2006.

Randel, W. J., Park, M., Emmons, L., Kinnison, D., Bernath, P., Walker, K. A., Boone, C., and Pumphrey, H.: Asian Monsoon Transport of Pollution to the Stratosphere, Science, 328, 611613, doi:10.1126/science.1182274, 2010.

Sparling, L. C.: Statistical perspectives on stratospheric transport, Rev. Geophys., 38, 417-436, 2000.

Tzella, A. and Legras, B.: A Lagrangian view of convective sources for transport of air across the Tropical Tropopause Layer: distribution, times and the radiative influence of clouds, Atmos. Chem. Phys., 11, 12517-12534, doi:10.5194/acp-11-12517-2011, 2011.

Vogel, B., Günther, G., Müller, R., Grooß, J.-U., Hoor, P., Krämer, M., Müller, S., Zahn, A., and Riese, M.: Fast transport from Southeast Asia boundary layer sources to northern Europe: rapid uplift in typhoons and eastward eddy shedding of the Asian monsoon anticyclone, Atmos. Chem. Phys., 14, 12745-12762, doi:10.5194/acp-14-12745-2014, 2014.

Waugh, D. W. and Hall, T. M.: Age of stratospheric air: Theory, observations, and models, Rev. Geophys., 40, 1-27, 2002.

WMO: Meteorology - A three-dimensional science, WMO Bull., 6, 134-138, 1957.

Yan, R.-C., Bian, J.-C., and Fan, Q.-J.: The impact of the South Asia high bimodality on the chemical composition of the upper troposphere and lower stratosphere, Atmos. Ocean. Sci. Lett., 4, 229-234, 2011.

Zhang, Q., Wu, G., and Qian, Y.: The bimodality of the 100 hpa South Asia high and its relationship to the climate anomaly over East Asia in summer, J. Meteorol. Soc. Jpn., 80, 733-744, 2002. 